\title{
Biosynthesis and Characterization of Silver Nanoparticles from Marine Macroscopic Brown Seaweed Colpomenia sinuosa (Mertens ex Roth) Derbes and Solier
}

\author{
M. Vishnu Kiran*, S. Murugesan \\ Unit of Algal Biotechnology and Bionanotechnology, PG and Research Department of Plant Biology and Biotechnology, Pachaiyappa's College, University of \\ Madras, Chennai - 600 030, Tamilnadu, India.
}

\section{ART I C LEDETAILS}

\section{Article history:}

Received 11 April 2020

Accepted 26 April 2020

Available online 02 May 2020

\section{Keywords:}

Silver Nanoparticles

Biological Green Synthesis

Colpomenia sinuosa

\begin{abstract}
A B S T RAC T
In the present study energy efficient, economically scalable colloidal silver (Ag) nanoparticles were biosynthesized from marine brown seaweed Colpomenia sinuosa by green synthesis method. The marine macroscopic brown seaweed Colpomenia sinuosa was used in the experimental study for the biosynthesis of silver nanoparticle since they are rich in phytochemicals, bioactive compounds and secondary metabolites which has reducing agents that may be environmentally acceptable and ecofriendly. The biosynthesized silver nanoparticles from marine macroscopic brown seaweed were characterized by UV-vis spectroscopy which confirmed the surface plasmon resonance of silver nanoparticles, Fourier transform infrared (FT-IR) spectroscopy to identify the presence of various functional groups in biomolecules responsible for the bio reduction of $\mathrm{Ag}^{+}$and capping/stabilization of silver nanoparticles. X-ray diffraction (XRD) to observe face center cubic (fcc) and crystalline nature of silver nanoparticles, thermogravimetric analysis (TGA) which revealed the thermal stability and purity of the silver nanoparticles. Particle size distribution and morphology were investigated by scanning electron microscope (SEM) which showed silver nanoparticles in the size range of 54-85 nm. The particle distribution under different nanometers was analyzed using transmission electron microscopy (TEM).
\end{abstract}

\section{Introduction}

Nanotechnology involves the characterization, fabrication of structures, materials or particles that have at least $1-100 \mathrm{~nm}$ in length. The field of nanotechnology is one of the most active research areas in modern materials science. Nanoparticle research is an ever-increasing scientific research interest, especially over the last couple of decades. The most effectively studied nanoparticles today are those made from noble metals, in particular Ag, Pt, Au and Pd. Nanoparticles and nanomaterials are quickly becoming part of everyday life. In the current scenario, the use of nanoparticles in biomedical applications such as drug delivery [1-3], cancer-cell diagnostics [4-7] and therapeutics [8] has given nanotechnology a new dimension. Biomolecules have been used for nanomaterial synthesis/functionalization and in subsequent applications for decades [9]. Nanoscience involves investigation into learning new properties of nano size, materials [10]. Nanotechnology is also being utilized in medicine for diagnosis, therapeutic drug delivery and the development of treatments for many diseases and disorders [11]. Silver nanoparticles are one of the promising products in the Nanotechnology industry. The development of consistent processes for the synthesis of silver nanomaterials is an important aspect of current nanotechnology research. One such promising process is the green synthesis. Silver nanoparticles can be synthesized by several physical, chemical and biological methods [12]. A possible application of silver nanoparticles is its potential as a catalyst. Jiang et al. [13] have proved the catalytic potential of nanosilver spheres. Nanosilver (silver nanoparticle, materials) have a wide range of applications including spectrally selective coating for solar energy absorption [14, 15], catalysis in chemical reactions [16], surface-enhanced Raman scattering for imaging [17], and antimicrobial sterilization [18-20]. Because of their effective antimicrobial properties and low toxicity to mammalian cells, sliver nanoparticles have become one of the most commonly used nanomaterials in consumer products [21, 22]. The scientific and practical interest in silver nanoparticles was exclusively caused by the possibility of their use as highly dispersed supports for enhancing the signals from organic molecules in the Raman spectroscopy [23]. A synergistic combination of nanotechnology and biotechnology provides unprecedented opportunities for addressing many of the current challenges in cancer diagnosis and therapy [24-28]. The literature survey revealed that the nanoparticle synthesis using biological sources like algae/seaweeds has been unexplored and unexploited [29-33]. In the present study the green synthesis of silver nanoparticles from marine macroscopic brown seaweed Colpomenia sinuosa (Mertens ex Roth) Derbes and Solier was biosynthesized and their characterization was studied by using UV-vis spectroscopy, Fourier transform infrared (FT-IR) spectroscopy, X-ray diffraction (XRD), thermogravimetric analysis, scanning electron microscope (SEM) and transmission electron microscopy (TEM).

\section{Experimental Methods}

\subsection{Collection and Preparation of Seaweed Extract}

The marine brown seaweed Colpomenia sinuosa (Mertens ex Roth) Derbes and Solier was collected from the intertidal regions of Leepuram, Kanyakumari District (Latitude $8^{\circ} 14^{\prime} 23.10^{\prime \prime}$ N, Longitude $77^{\circ} 20^{\prime} 04.02$ " E); South East Coast of Tamilnadu during summer. Collected seaweed was washed with sea water for eliminating impurities such as sand, rocks, epiphytes and epifauna. The washed samples were preserved with $5-10 \%$ formaldehyde in sea water and transported to the laboratory in a box containing slush ice. The fumes of the formaldehyde would help to fix and preserve the seaweed material. In the laboratory, the samples were washed thoroughly in running tap water to remove salt and washed three times using distilled water which may remove metallic compounds and it was shade dried at room temperature $\left(37^{\circ} \mathrm{C}\right)$ for 10 days. The dried seaweed materials were crushed by using mortar and pestle to get the powder form and it was stored in an air-tight container. About $1 \mathrm{~g}$ of crushed seaweed powder was added with $100 \mathrm{~mL}$ of distilled water in 250 $\mathrm{mL}$ conical flask and boiled for $5-10$ minutes at $60-80^{\circ} \mathrm{C}$. The crude extract was collected and stored at $4{ }^{\circ} \mathrm{C}$ for experimental use [34]. 


\subsection{Biosynthesis of Silver Nanoparticles}

The crude extract of the experimental marine brown seaweed Colpomenia sinuosa (Mertens ex Roth) Derbes and Solier was used for the synthesis of silver nanoparticles. Silver nitrate $\left(\mathrm{AgNO}_{3}\right.$ ) ( $\mathrm{SD}$ fine) was used for the synthesis of silver nanoparticles and double-distilled, deionized water was used for all the experiments. The silver nanoparticle formation was carried out by taking $500 \mathrm{mg}$ of dry, shade dried powder samples of Colpomenia sinuosa in a $250 \mathrm{~mL}$ Erlenmeyer flask with $10^{-3} \mathrm{M}$ aqueous $\mathrm{AgNO}_{3}$ - solution and was incubated at room temperature. The $\mathrm{pH}$ was checked during the course of reaction, and it was found to be 5.09. Nearly 95\% of bio reduction of $\mathrm{AgNO}_{3}$ - ions occurred within $24 \mathrm{hr}$ at stirring condition. The biosynthesis of silver nanoparticles was characterized by UV Vis spectroscopy; size and morphology by employing SEM and TEM, structure from X-ray diffraction (XRD) technique, stability of silver nanoparticles from Thermo gravimetric analysis (TGA) and biomolecules involved in the capping agent of silver nanoparticles from Fourier transform infrared (FT-IR) spectroscopy.

\section{Results and Discussion}

\subsection{Visual Examination}

The biosynthesis of silver nanoparticles was primarily identified by color change during exposure of crude seaweed extract of Colpomenia sinuosa into aqueous solution of silver ions is shown in Fig. 1. The shade dried powder preparations of the experimental seaweed Colpomenia sinuosa were added in $10^{-3} \mathrm{M}$ silver nitrate solution and allowed to react at $121^{\circ} \mathrm{C}$ for 20 minutes. The colour of the reaction solution changed to dark reddish brown. The control (without seaweed powder) showed no colour formation. Formation of the colour arises due to the excitation of surface plasmon vibrations where the metabolites in the seaweed extract act as the capping agent. The colour of the solution gradually intensified on heating which clearly indicates and confirms the formation of silver nanoparticles. After $24 \mathrm{hr}$, there is no significant color change, indicating the saturation of the reaction of silver nanoparticle formation.

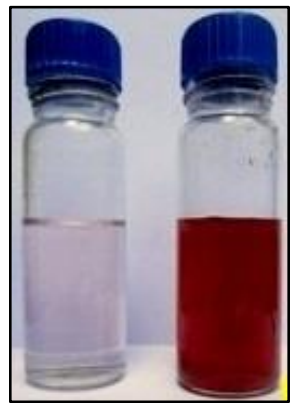

Fig. 1 Aqueous extract of Colpomenia sinuosa before and after synthesis of silver nanoparticles

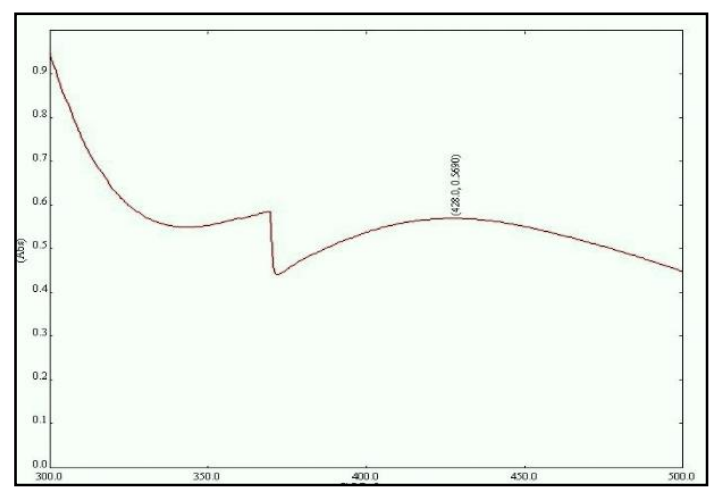

Fig. 2 UV Visible spectral analysis of silver nanoparticles bio-synthesized from Colpomenia sinuosa

\subsection{UV-Visible Spectroscopic Analysis}

The silver nanoparticles synthesized by marine brown seaweed Colpomenia sinuosa were analyzed by using UV-Vis spectrophotometer (Labtron LUS-B16). The absorption spectra of silver nanoparticles formed in the reaction solution were characteristic for the seaweed and had specific absorption maxima $428 \mathrm{~nm}$ is shown in Fig. 2. The broadening of the peak indicated that the silver nano particles synthesized from the experimental seaweed are polydispersed in nature and the intensity of the band increased with the increase in reaction time. The frequency and https://doi.org/10.30799/jacs.219.20060101 width of the surface plasmon absorption depends largely on the size and shape of the metal nanoparticles as well as on the dielectric constant of the metal and the surrounding medium [35-37]. The interaction with the biomolecules presents in the aqueous part of the reaction solution by the biosynthesized silver nanoparticles from experimental seaweed has been indicated by UV-Visible spectroscopic analysis. There were no little signs of aggregation with the biosynthesized silver nanoparticles solution which were stable for more than six months of observation.

\subsection{FT-IR Spectroscopic Analysis (FTIR)}

The FTIR spectral measurements were carried out to identify the potential biomolecules in the crude extract of the seaweed Colpomenia sinuosa which is responsible for reducing and capping the bio reduced silver nanoparticles. Silver nanoparticles biosynthesized from experimental seaweed Colpomenia sinuosa were analyzed using FT-IR spectroscopy is shown if Fig. 3 and Table 1. The local molecular environment of the organic molecules on the surface of the nanoparticles was determined by the IR spectra. Fourier transform infrared spectroscopy (FTIR) is a technique which is used to analyze the chemical composition of many organic chemicals, semiconductor materials, gases, biological samples, inorganics, and minerals. FTIR analysis can give not only qualitative (identification) analysis of materials, but, with relevant standards, can be used for quantitative (amount) analysis. The FT-IR spectral absorbance bands of the nanoparticles of Colpomenia sinuosa were seen at $3435 \mathrm{~cm}^{-1}$ (O-H stretch, H-bonded alcohols, phenols), 2923 $\mathrm{cm}^{-1}$ (C-CH 3 stretch, alkanes), $2853 \mathrm{~cm}^{-1}$ (CH , alkanes), $2519 \mathrm{~cm}_{-1}$ (S-H stretch, thiol), $2091 \mathrm{~cm}^{-1}$ (C $\equiv \mathrm{C}$ stretch, alkynes), $1633 \mathrm{~cm}^{-1}$ (N-H bend, primary amines), $1469 \mathrm{~cm}^{-1}$ (C-C stretch (in-ring), aromatics), $1103 \mathrm{~cm}^{-1}$ (C-N stretch, aliphatic amines), $1034 \mathrm{~cm}^{-1}$ (C-O stretch, alcohols, ethers), $875 \mathrm{~cm}^{-1}$ (C-H out of plane bending, aromatics) [38], $862 \mathrm{~cm}^{-1}$ (C-H out of plane bending, aromatics), $712 \mathrm{~cm}^{-1}$ (C-Cl stretch, alkyl halides), $658 \mathrm{~cm}^{-1}$ (C-Br stretch, alkyl halides), $603 \mathrm{~cm}^{-1}$ (C-Br stretch, alkyl halides), 541 $\mathrm{cm}^{-1}$ (C-Br stretch, alkyl halides), and $471 \mathrm{~cm}^{-1}$ (S-S stretch, polysulfides). The FT-IR spectrum analysis indicates the presence of chemical bonds and the functional groups of the biomolecules responsible for the stabilization of the biosynthesized silver nanoparticles from the experimental marine brown seaweed Colpomenia sinuosa. The FTIR results revealed that the compounds present in the marine brown seaweed Colpomenia sinuosa which are aromatic, alkanes, amides or amines [39] that may act as the capping ligand in the formation of silver nanoparticles and also possible perform the stabilization of silver nanoparticles in the aqueous medium. These results obtain good agreement with the literatures [38,40].

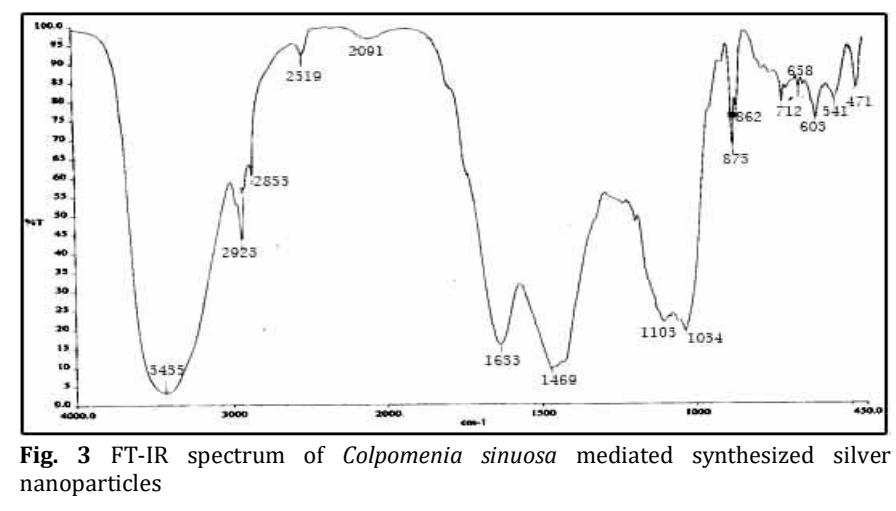

Table 1 FT-IR Spectral interpretation of silver nanoparticles bio-synthesized from Colpomenia sinuosa

\begin{tabular}{ll}
\hline Wave number $\left(\mathrm{cm}^{-1}\right)$ & Spectral Assignments \\
\hline 3435 & O-H stretch, H-bonded alcohols, phenols \\
2923 & C-CH3 stretch, alkanes \\
2853 & CH2, alkanes \\
2519 & S- H stretch, thiol \\
2091 & C C stretch, alkynes \\
1633 & N-H bend, primary amines \\
1469 & C-C stretch (in-ring), aromatics \\
1103 & C-N stretch, aliphatic amines \\
1034 & C-O stretch, alcohols, esters, ethers \\
875 & C-H "oop", aromatics \\
862 & C-H “oop", aromatics \\
712 & C-Cl stretch, alkyl halides \\
658 & C-Br stretch, alkyl halides \\
603 & C-Br stretch, alkyl halides \\
541 & C-Br stretch, alkyl halides \\
471 & S-S stretch, Polysulfides \\
\hline
\end{tabular}




\subsection{X-Ray Diffraction Pattern (XRD)}

XRD is a widely used to determine the size and crystal structure of silver nanoparticles. X-ray diffractogram of the biosynthesized silver nanoparticles by the experimental seaweed Colpomenia sinuosa exhibits Bragg reflection corresponding to face centered cubic (fcc) type bulk silver. The broadened diffraction peaks around their base indicates that the silver nanoparticles are between nano sizes. XRD (Labtron LXRD-A10) analysis of biosynthesized silver nanoparticles from Colpomenia sinuosa exhibited four distinct diffraction peaks is shown in Fig. 4. The lattice planes ( $\left.\begin{array}{lll}1 & 0 & 0\end{array}\right),\left(\begin{array}{lll}1 & 1 & 0\end{array}\right),\left(\begin{array}{lll}1 & 1 & 1\end{array}\right)$ and ( $\left.\begin{array}{lll}2 & 0 & 0\end{array}\right)$ were identified with the corresponding Bragg's angles of $11.58^{\circ}, 32.04^{\circ}, 37.89^{\circ}$ and $46.96^{\circ}$ respectively, which confirm the face-centered cubic structure of the silver nanoparticles. The observed peak broadening and noise were probably related to the effect of nano sized particles and the presence of various biological molecules in the reaction solution. The XRD pattern thus clearly shows that the silver nanoparticles are crystalline in nature.

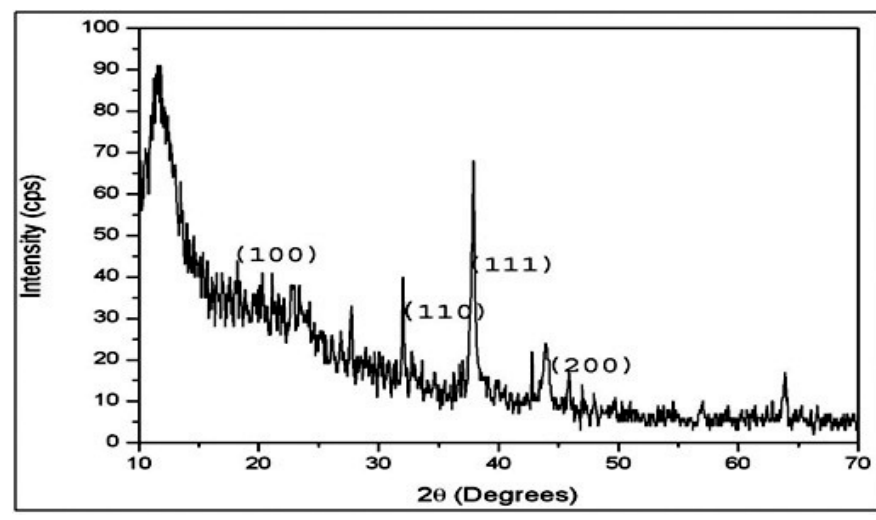

Fig. 4 X-ray diffraction analysis of sliver nanoparticles biosynthesized from Colpomenia sinuosa

\subsection{Thermo Gravimetric Analysis (TGA)}

The biosynthesized silver nanoparticles from the experimental seaweed Colpomenia sinuosa were subjected to thermogravimetric analysis (TGA 4000 - PerkinElmer) is shown in Fig. 5. The thermogravimetric analysis was used to assess the purity and thermal stability of sliver nanoparticles. The thermogram of biosynthesized silver nanoparticles from Colpomenia sinuosa was observed and there was no major weight loss up to $220{ }^{\circ} \mathrm{C}$ and a sharp weight loss of $12 \%$ was observed in the temperature range of $220-400{ }^{\circ} \mathrm{C}$. TGA result shows that the purity of silver nanoparticles was $95 \%$ for biosynthesis of silver colloidal medium carried out by the ultra-sonication method [41]. There was nearly no degradation above $400{ }^{\circ} \mathrm{C}$ that accounts for the weight of the silver.

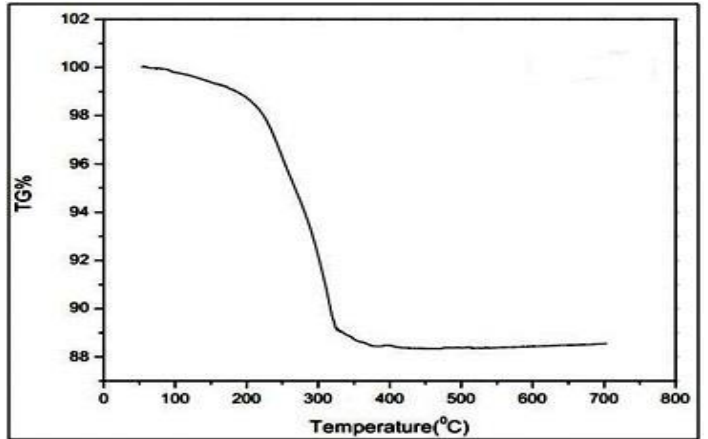

Fig. 5 TGA thermogram of silver nanoparticles bio-synthesized from Colpomenia sinuosa

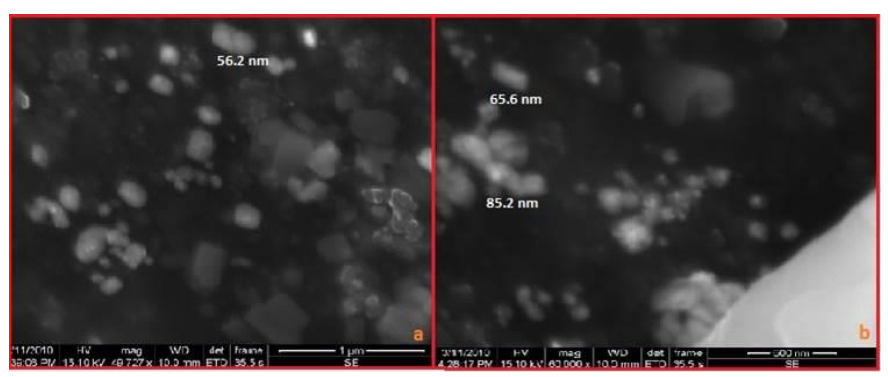

Fig. 6 Scanning Electron Micrograph of silver nanoparticles bio-synthesized from Colpomenia sinuosa

https://doi.org/10.30799/jacs.219.20060101

\subsection{Scanning Electron Microscopy (SEM)}

The morphology and shape of these silver nanoparticles were carried out using scanning electron microscopy (SEM Quanta - 400) is shown in Fig. 6. The silver nanoparticles synthesized from Colpomenia sinuosa biomass after exposure to $10^{-3} \mathrm{M}$ aqueous silver nitrate solution for 2 hours showed the colloidal form of the particles in solution which micro precipitated on the surface of the biomass of the experimental seaweed. The back scattered electron image showed bright cubical and spherical area which corresponds to the silver nanoparticles indicating the structure of nanosilver. The hydrogen bond and electrostatic interactions might have played a key role along with the bioorganic capping molecules of the experimental seaweed in the formation of the morphology and shape of silver nanoparticles. The other factor in determining the shape of the silver nanoparticles may be attributed to the changes in the optical and electronic properties. The stabilization of the nanoparticles by the capping agent might be due to nanoparticles were not in direct contact within the aggregates. Thus, the shape and morphology of the biosynthesized nanoparticles by the experimental brown seaweed Colpomenia sinuosa was clearly revealed by the SEM results.

\subsection{Transmission Electron Microscopy (TEM)}

Further insight on morphology and the size details of the biosynthesized silver nanoparticles by the experimental seaweed Colpomenia sinuosa were investigated using high resolution transmission electron microscopy (HR-TEM JEOL 3010) is shown in Fig. 7. The HR-TEM images of silver nanoparticles clearly revealed the formation of spherical and hexagonal shaped nanoparticles. The majority of the nanoparticles appeared spherical and only a small percentage was elongated particles that ranged in size from 5 to $50 \mathrm{~nm}$. The average means size of silver nanoparticles was $34 \mathrm{~nm}$.

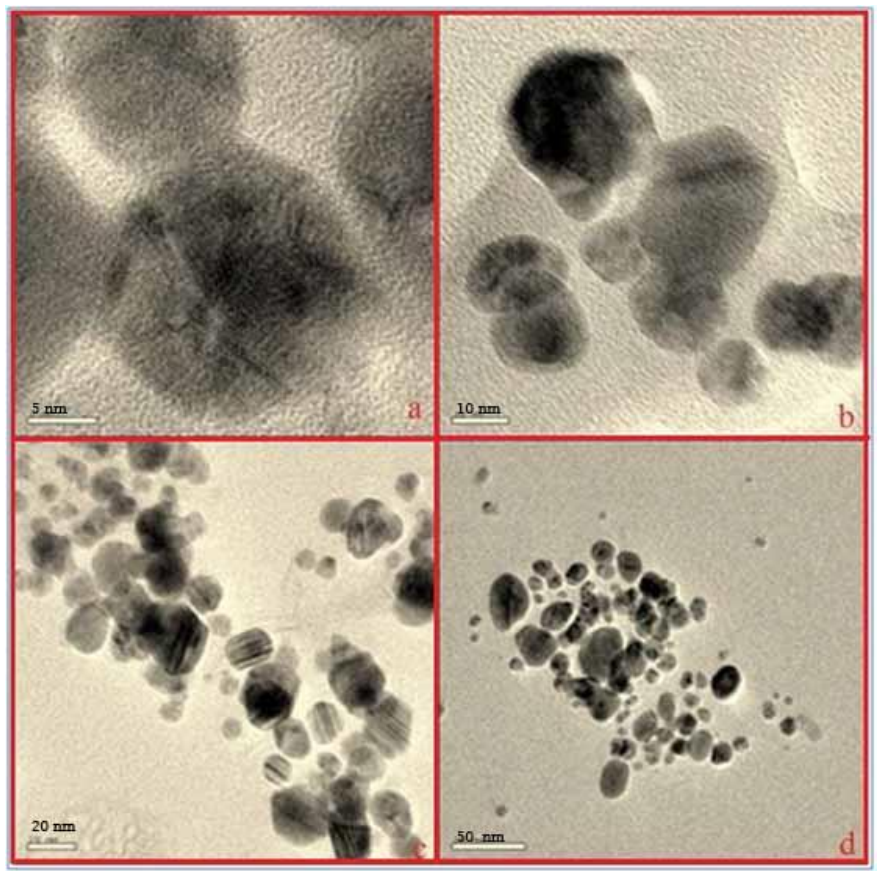

Fig. 7 HR-TEM images of silver nanoparticles bio-synthesized from Colpomenia sinuosa

\section{Conclusion}

In this work silver nanoparticles were synthesized by the reduction of silver nitrate using the extract of marine brown seaweed Colpomenia sinuosa. The reaction mixture was successfully optimized to increase the yield of silver nanoparticles production using UV-Vis analysis results. The optimum conditions were as follows: 500 g extract concentration, $10^{-3} \mathrm{M}$ aqueous $\mathrm{AgNO}_{3}-$ solution, $37{ }^{\circ} \mathrm{C}$ and $\mathrm{pH}$ 5.09. The Colpomenia sinuosa seaweed extract acts as both reducing and stabilizing agents for the synthesis of silver nanoparticles, which were confirmed by FTIR. SEM analysis revealed that the silver nanoparticles ranged between $54 \mathrm{~nm}$ to $65 \mathrm{~nm}$ in size and were spherical with uniform distribution. TEM analysis revealed nearly spherical and hexagonal structures of the silver nanoparticles. The XRD pattern of silver nanoparticles showed a facecentered cubic crystal structure. The purity and thermal stability of silver nanoparticles were detected by TGA analysis, which was closely related to that of bulk metallic silver, which indicates its purity. The benefits of using 
seaweeds via green synthesis for bio synthesis of silver nanoparticles is an environmental-friendly process that promotes energy efficiency, cost effectiveness, and protects human health while leads to inherently safer products and lesser waste. This environmental-friendly method of synthesizing silver nanoparticles as alternative measure to conventional physical and chemical methods has an enormous potential to be used in low cost production applications.

\section{Acknowledgement}

This work was carried out in part through the use of the scanning electron microscopy (SEM) and transmission electron microscopy (TEM) at Sophisticated Analysis Instrument Facility (SAIF), Indian Institute of Technology (IIT) - Madras, Tamilnadu, India. The thermogravimetric analysis (TGA) was carried out at Department of Chemistry, Anna University, Chennai, Tamilnadu, India. The authors thank the above institutions for their instrumentation facility for the completion of the work. We also sincerely thank Mr. Raju sea diver who helped me in the collection of the sea weeds from south east coast of Tamilnadu, India.

\section{References}

[1] J.L. West, N.J. Halas, Engineered nanomaterials for biophotonics applications: Improving sensing, imaging, and therapeutics, Annu. Rev. Biomed. Eng. 5 (2003) 285-292.

[2] G.F. Paciotti, L. Myer, D. Weinreich, D. Goia, N. Pavel, R.E. McLaughlin, L. Tamarkin, Colloidal gold: A novel nanoparticle vector for tumour directed drug delivery, Drug Delivery 11 (2004) 169-183.

[3] K.K. Jain, Nanotechnology-based drug delivery for cancer, Technol. Cancer. Res. Treat. 4 (2005) 407-16

[4] X. Wu, H. Liu, J. Liu, K.N. Haley, J.A. Treadway, et al., Immunofluorescent labeling of cancer marker Her2 and other cellular targets with semiconductor quantum dots, Nat. Biotechnol. 21(1) (2003) 41-46.

[5] W.C.W. Chan, D.J. Maxwell, X. Gao, R.E. Bailey, M. Han, S. Nie, Luminescent quantum dots for multiplexed biological detection and imaging, Curr. Opin. Biotechnol. 13(1) (2002) 40-46.

[6] K. Sokolov, M. Follen, J. Aaron, I. Pavlova, A. Malpica, R. Lotan, K.R. Richartz, Real-time vital optical imaging of precancerous drug using anti-epidermal growth factor receptor antibodies conjugated to gold nanoparticles, Cancer Res. 63 (2003) 1999-2004.

[7] A.P. Alivisatos, The use of nano crystals in biological detection, Nat. Biotechnol. 22(1) (2004) 47-52.

[8] L.R. Hirsch, R.J. Stafford, J.A. Bankson, S.R. Sershen, B. Rivera, et al., Nano shellmediated near-infrared thermal therapy of tumours under magnetic resonance guidance, Proc. Natl. Acad. Sci. 100(23) (2003) 13549-54.

[9] C.M. Niemeyer, Nanoparticles, proteins, and nucleic acids: Biotechnology meets materials science, Angew. Chem. Int. Edn. 40 (2001) 4128-4158.

[10] National Nanotechnology Initiative, What is nanotechnology? http://www.nano.gov/html/facts/whatIsNano.html (Accessed on: 02.08.2008)

[11] G.I. Arun, A.N. Chaudhari, Biogenic synthesis of nano particles and potential applications: An eco-friendly approach, J. Nanomed. Nanotech. 4(2) (2013) 17.

[12] A.V. Thirumalai, D. Prabhu, M.J. Soniya, Stable silver nano particle synthesizing methods and its applications, Biosci. Res. 1(4) (2010) 259-270.

[13] Z.J. Jiang, C.Y. Liu, L.W. Sun, Catalytic properties of silver nanoparticles supported on silica spheres, J. Phys. Chem. B 109 (5) (2005) 1730-1735.

[14] B.P. Rand, P. Peumans, S.R. Forrest, Long-range absorption enhancement in organic tandem thin-film solar cells containing silver nano clusters, J. Appl. Phys. 96 (2004) 7519-7526.

[15] J.R. Cole, N.J. Halas, Optimized plasmonic nano particle distributions for solar spectrum harvesting, Appl. Phys. Lett. 89 (2006) 153120:1-3.

[16] H.J. Zhai, D.W. Sun, H.S. Wang, Catalytic properties of silica/silver nanocomposites, J. Nanosci. Nanotechnol. 6 (2006) 1968-1972.

[17] S. Yamamoto, H. Watarai, Surface-enhanced Raman spectroscopy of dodecanethiol-bound silver nanoparticles at the liquid/liquid interface, Langmuir 22 (2006) 6562-6569.
[18] N. Savage, M.S. Diallo, Nanomaterials and water purification: opportunities and challenges, J. Nanoparticle. Res. 7 (2005) 331-342.

[19] V. Samby, M.M. MacBride, B.R. Peterson, Silver bromide nanoparticle/polymer composites: dual action tunable antimicrobial materials, J. Am. Chem. Soc. 128 (2006) 9798-9808.

[20] S. Pal, Y.K. Tak, J.M. Song, Does the antibacterial activity of silver nanoparticles depend on the shape of the nanoparticle? A study of the gram-negative bacterium Escherichia coli, Appl. Environ. Microbiol. 73 (2007) 1712-1720.

[21] A.D. Maynard, E. Michelson, The nanotechnology consumer products inventory, Woodrow Wilson International Center for Scholars, Http://www.Nanotechproject.Org/44 (Accessed on: 29.05.2007)

[22] M. Fayaz, K. Balaji, M. Girilal, R. Yadav, P.T. Kalaichelvan, R. Venketesan, Biogenic synthesis of silver nanoparticles and their synergistic effect with antibiotics: a study against gram-positive and gram-negative bacteria Nanomed. Nanotechnol. Biol. Med. 6(1) (2010) 103-109.

[23] P.C. Lee, D. Meisel, Adsorption and surface enhanced Raman of dyes on silver and gold sols, J. Phys. Chem. 86 (1982) 3391-3395.

[24] H.M.E. Azzazy, M.M.H. Mansour, S.C. Kazmierczak, From diagnostics to therapy: Prospects of quantum dots, Clin. Biochem. 40 (2007) 917-927.

[25] A. Zajac, D. Song, W. Qian, T. Zhukov, Protein microarrays and quantum dot probes for early cancer detection, Colloid. Surf. B 58(2) (2007) 309-314.

[26] K. Kerman, T. Endo, M. Tsukamoto, M. Chikae, Y. Takamura, E. Tamiya, Quantum dot-based immunosensor for the detection of prostate-specific antigen using fluorescence microscopy, Talanta 71(4) (2007) 1494-1499.

[27] K. Sokolov, D. Nida, M. Descour, A. Lacy, M. Levy, et al., Molecular optical imaging of therapeutic targets of cancer, Adv. Cancer Res. 96 (2006) 299-344.

[28] D.L. Nida, M.S. Rahman, K.D. Carlson, R. Richards-Kortum, M. Follen Fluorescent nanocrystals for use in early cervical cancer detection, Gynecol. Oncol. 99(3) (2005) 89-94.

[29] P. Rajasulochana, R. Dhamotharan, P. Murugakoothan, S. Murugesan, P. Krishnamoorthy, Biosynthesis and characterization of gold nanoparticles using the alga Kappaphycus alvarezii, Int. J. Nanosci. 9(5) (2010) 511-519.

[30] S. Swaminathan, S. Murugesan, S. Damodarkumar, R. Dhamotharan, S Bhuvaneswari, Synthesis and characterization of gold nano particles from alga Acanthophora specifera (VAHL) Boergesen, Int. J. Nanosci. Nanotech. 2(2) (2011) 85-94.

[31] R. Dhamotharan, D. Punitha, S. Murugesan, T.S. Subha, Brown algal biomass mediated biosynthesis of gold nanoparticles, Int. J. Nanosci. Nanotech. 1(1) (2010) 37-44

[32] D. Radhika, C. Veerabahu, L. Sakthibama, S. Murugesan, Green synthesis of gold nanoparticles by the marine alga Stoechospermum marginatum, Int. J. Nanotech. Appl. 6(91) (2012) 61-70.

[33] M. Vishnu Kiran, S. Murugesan, Bio-synthesis of silver nano particles from marine alga Halymenia poryphyroides and its antibacterial efficacy, Int. J. Curr. Microbiol. App. Sci. 3(4) (2014) 1-7.

[34] K.S. Rajesh, C. Malrakodi, K.S. Venkat, Synthesis and characterization of silver nanoparticles from marine brown seaweed and its antifungal efficiency against clinical fungal pathogens, Asian. J. Pharm. Clin. Res. 10(2) (2017) 190-193.

[35] P. Mukherjee, A. Ahmad, D. Mandal, S. Senapati, S.R. Sainkar, M.I. Khan, Fungusmediated synthesis of silver nanoparticles and their immobilization in the mycelial matrix: A novel biological approach to nanoparticle synthesis, Nano. Lett. 1(10) (2001) 515- 519.

[36] P. Mukherjee, A. Ahmad, D. Mandal, S. Senapati, S.R. Sainkar, M.I. Khan, R. Kumar, Extracellular synthesis of gold nanoparticles by the fungus Fusarium oxysporum, Chem. Biochem. 3(5) (2002) 461- 463

[37] J. Gonzalo, R. Serna, J. Sol, D. Babonneau, C.N. Afonso, Morphological and interaction effects on the surface plasmon resonance of metal nanoparticles, J. Phys. Condens. Matter 15(42) (2003) 3001-3002.

[38] S. Zavoi, F. Fetea, F. Ranga, R. Pop, A. Baciu, C. Socaciu, Comparative fingerprint and extraction yield of medicinal herb phenolics with hepatoprotective potential, as determined by UV-Vis and FT-MIR spectroscopy, Not. Bot. Horti Agrobot. Cluj-Napoca. 39 (2011) 82-89.

[39] M. Mirderikvandi, A. Kiani, M. Khaldari, M. Alirezae, Effects of artichoke (Cynara scolymus L.) extract on antioxidant status in chicken thigh meat, Iran. J. Vet. Med. 10 (2016) 73-81.

[40] Q. Chen, G. Liu, G. Chen, T. Mi, J. Tai, Green synthesis of silver nanoparticles with glucose for conductivity enhancement of conductive ink, Bioresources 12 (2016) 608-621.

[41] K.L. Niraimathi, R. Lavanya, S. Veerappan, P. Brindha, Green synthesis and characterization of silver nanoparticles from aqueous extract of Basella alba and their invitro antioxidant potentials, Int. J. Pharm. Pharm. Sci. 6 (2014) 393396. 